Cite as "Chen, S., Schreurs, L., Pabian, S., \& Vandenbosch, L. (in press). Daredevils on Social Media: A Comprehensive Approach towards Risky Selfie Behavior among Adolescents. New Media \& Society."

\title{
Daredevils on Social Media: A Comprehensive Approach towards Risky Selfie Behavior among Adolescents
}

\section{Shuang Chen}

School of Media, University of Chinese Academy of Social Sciences, Beijing, China

\section{Lara Schreurs}

School for Mass Communication Research, Faculty of Social Sciences, KU Leuven, Leuven, Belgium; Research Foundation Flanders (FWO-Vlaanderen), Belgium

\section{Sara Pabian}

Research group MIOS (Media, ICT \& Interpersonal Relations in Organisations and Society), Department of Communication Sciences, Faculty of Social Sciences, University of Antwerp, Antwerp, Belgium; Research Foundation Flanders (FWO-Vlaanderen), Belgium

\section{Laura Vandenbosch}

School for Mass Communication Research, Faculty of Social Sciences, KU Leuven, Leuven, Belgium

\section{Corresponding Author}

Shuang Chen, School of Media, University of Chinese Academy of Social Sciences, No. 11 Changyu Street, Fangshan District, 102488 Beijing, China. Email:

chenshuanghere@163.com 


\section{RISKY SELFIES AMONG ADOLESCENTS}

\section{Abstract}

Risky selfies are recent, but worrying phenomena in which adolescents take pictures of themselves during the act of risk behavior. By applying the principles of the prototype willingness model, the current cross-sectional study among adolescents $(N=686)$ aged 15 to 18 years old examined the relation between social media use and adolescents' risky selfie behavior. A structural equation model indicated that adolescents' general social media use was positively related to descriptive norm estimations of risky selfie takers and favorable prototype perceptions of risky selfie takers. Moreover, attitudes toward the taking of risky selfies and prototype perceptions of risky selfie takers were found to positively relate to adolescents' willingness to engage in risky selfie taking and their actual risky selfie behavior. Furthermore, no support was found for the moderating roles of gender, developmental status, narcissism, and sensation seeking in the reported relations with social media use.

\section{Keywords}

Social media, Adolescence, Risk behavior, Selfies, Prototype willingness model 


\section{RISKY SELFIES AMONG ADOLESCENTS}

\section{Introduction}

Social media platforms such as Facebook, Instagram, and Snapchat form a substantial part of adolescents' daily lives (Anderson and Jiang, 2018). They allow adolescents to strengthen their social ties and experiment with their identity (Subrahmanyam and Šmahel, 2011). However, scholars have warned that some social media practices may harm adolescent well-being (e.g., Nowland et al., 2018).

One of these worrying practices is the posting of risky selfies. Based on emerging literature (Lamba et al., 2016; Zuckerman, 2014), risky selfies can be defined as pictures displaying the social media user in a dangerous situation, such as the climbing on a cliff or the inattentive driving of a vehicle. Risky selfies target particularly intense, dangerous behaviors, and involve taking social and/or legal risks. Because of the user's focus on his/her smartphone camera or on posing for the camera, his/her attention to the dangerous situation will be lowered and the risks of being physically harmed will increase (Flaherty and Choi, 2016).

As social media are highly popular among adolescents (Anderson and Jiang, 2018) and adolescence is considered a key period for risk behavior (Arnett, 1992), it is most likely that some adolescents are willing to take risks for the glory of posting a risky selfie on social media. Given that research is lacking on this subject, the current cross-sectional study explores risky selfie behavior among 686 adolescents. Its goals are threefold. First, the study explores whether general social media use is linked to posting risky selfies. During their social media use, adolescents may encounter multiple examples of peers engaging in moderately to highly risky behavior. Such examples may support them to also post risky selfies (Lamba et al., 2016). Second, the study explores the potential value of the prototype willingness model to explain how (some of) the links between social media use and risky selfie behavior develop (Gerrard et al., 2008). This theoretical model was originally developed to explain offline risk behavior among adolescents (Gerrard et al., 2008), but recent studies suggest it may also be applicable to online risk behavior (e.g., van Oosten et al. 2017). Third, media effects theories (e.g., Valkenburg and Peter, 2013) suggest (social) media effects largely depend on differential susceptibility factors, though they are often neglected in media effect studies. The current study acknowledges this theoretical proposition and explores whether theoretically suggested sociodemographic factors (i.e., gender and developmental status) and personality variables (i.e., 


\section{RISKY SELFIES AMONG ADOLESCENTS}

narcissism and sensation seeking) moderate the links in the proposed model on risky selfie behavior.

\section{Risky Selfies on Social Media}

Public press has recently covered multiple stories with an unfortunate deadly ending of risky selfie behavior. One case was the death of an Australian student who died while taking a picture on the Trolltunga cliff. This cliff is a highly popular attraction among tourists, but at the same time also a dangerous place to visit (Romanos, 2015). In 2016, a USA data tracking company (Priceconomics) analyzed all selfie instances with fatal accidents $(N=49)$ that were reported in public press since 2014. Falling down of heights, drowning and train accidents were listed as the most prevalent causes in their results. In their study, one fifth of the examined cases involved adolescents (Priceonomics, 2016). Lamba and colleagues (2016) note that from March 2014 until November 2016127 people died while taking a risky selfie and many have been injured. The authors provide no further information on socio-demographic factors and/or personal characteristics of those involved.

Although such knowledge is lacking, scholars have expressed concerns about risky selfie behavior. Tourism scholars in general appreciate the affordances of mobile media to enhance travelling experiences (e.g., Wang et al., 2012), but they have also warned that the taking of selfies distracts travelers from safeguarding their safety when visiting dangerous touristic places (Ayeh, 2018).

The reasons for why individuals would take risky selfies are likely closely intertwined with individuals' reasons for using social media and in particular the posting of selfies (Sung et al., 2016). Adolescents use social media mainly because of identity and popularity needs (Subrahmanyam and Šmahel, 2011). These drivers of social media use may in particular be gratified by the practice of posting risky selfies. More precisely, when creating an online identity, (adolescent) users especially value an authentic and original identity (Reinecke and Trepte, 2014). Risky selfies may contribute to establishing such an original online identity as they are likely to associate the individual with rather exceptional and adventurous activities. At the same time, adolescents may post dangerous selfies to enhance their social ties and more specifically their popularity status. Adolescents have been noted consistently to engage in risk behavior because of social rewards (Arnett, 1992). It is not unlikely that risky selfies receive many likes 


\section{RISKY SELFIES AMONG ADOLESCENTS}

because of their rather exceptional nature. One study supports this reasoning by noticing that cues that hint at a wild personality are expected to impress peers (Peluchette and Karl, 2009).

Together, research suggests that risky selfies are taken and that individuals would engage in such behavior because of multiple reasons. However, literature is lacking to document and understand this selfie- taking behavior that may have profound consequences for adolescents' health. Such insights may be important considering the popularity of social media among adolescents in Europe and the US (Anderson and Jiang, 2018; Apestaartjaren, 2018).

\section{Prototype Willingness Model}

In order to gain a deeper understanding of adolescents' risky selfie taking behavior, the present study relies on the prototype willingness model (PWM) (Gerrard et al., 2008; Gibbons and Gerrard, 1995). The framework describes a set of cognitive factors (i.e., attitudes, descriptive norms, subjective norms, and prototype perceptions) that mediate and thus explain the effects of an individual's social environment (e.g., social media use) on their risk behavior (e.g., risky selfie behavior) (Gerrard et al., 2008).

According to the PWM, adolescent risk behavior can be explained by a reasoned and social reaction path. The latter path is more intuitive and spontaneous, whereas the reasoned path is driven by rational thoughts. The reasoned path first assumes that an individual's performance of a behavior depends on the individual's attitudes towards the consequences of the behavior. If an individual has favorable attitudes towards the behavior he/she will (be more willing to) perform the behavior (Gerrard et al., 2008). Thus, the more favorable an individual feels about risky selfie taking, the more willing he/she is to take such selfies oneself.

Moreover, it is argued that an individual's norm beliefs, that is a) perceptions of the number of peers that conduct the behavior (i.e., descriptive norms) and b) perceptions of significant others' approval of the behavior (i.e., subjective norms) influence one's own willingness to engage in the behavior (Gerrard et al., 2008). Accordingly, if someone believes that significant others take risky selfies and that they approve this behavior, he/she will (have a higher willingness to) take risky selfies oneself. 


\section{RISKY SELFIES AMONG ADOLESCENTS}

The social reaction path assumes behavior can be induced and facilitated by circumstances. The path proposes to focus on prototypes described as mental images of typical persons engaging in the particular risk behavior (Gibbons and Gerrard, 1995). If perceptions of the prototypes are positive, a greater willingness or openness to perform risk behavior is expected (Gibbons and Gerrard, 1995). In other words, if an adolescent has favorable perceptions of peers who perform risky selfie behavior, the more willing he/she would be to perform this behavior oneself.

The social environment sources that impact the cognitive factors central in the PWM (i.e., attitudes, subjective/descriptive norms, and prototypes) are not extensively described in the model, but have been addressed in the research following the PWM model. This literature indicates that the more frequent an individual is present in a social environment in which a risk behavior is performed, the higher the probability that he/she believes others approve and conduct the behavior, and that he/she will adopt a favorable attitude and prototype towards the behavior (Gerrard et al., 2008). One of these social environment sources is social media because of their popularity among adolescents and their influential role in adolescent development (Festl and Quandt, 2016).

Among adolescents, the PWM has successfully explained offline and online risk behavior, such as alcohol use and sexting (Gerrard et al., 2008; Walrave et al., 2015). A recent study among adolescents supported the relevance of social media use as a trigger of the cognitive factors described in the PWM (Festl and Quandt, 2016). In the study of Festl and Quandt (2016) positive associations between social media use and favorable attitudinal and normative beliefs on online risk behavior were found. However, not all studies that applied the PWM have found evidence for both a reasoned and social reaction path to explain adolescent risk behavior. For instance, in the study of van Oosten and colleagues (2017) no evidence was found for a social reaction path as prototype perceptions for casual sex did not predict adolescents' willingness to engage in casual sex.

Together, the literature suggests that the more adolescents use social media, the more they are confronted with risky selfies, but also with the importance of creating an original identity on social media (see reasoning above, Peluchette and Karl, 2009; Reinecke and Trepte, 2014). Accordingly, a high dose of daily social media use may result into cognitions that favor an adventurous personality and thus the taking of risky selfies. Such cognitions would, in turn, be expected to positively influence the willingness to take risky selfies and the actual risky selfie behavior. Accordingly, it is hypothesized that attitudes, descriptive norms, subjective norms, and prototype 


\section{RISKY SELFIES AMONG ADOLESCENTS}

perceptions mediate the relations between social media use and one's willingness to take risky selfies. This reasoning is summarized in Figure 1.

[Figure 1.]

\section{Individual Susceptibility to Risky Selfie Behavior}

Social media effects are not uniform and largely depend on personal characteristics of social media users according to research (e.g., Nowland et al., 2018). This empirical conclusion coincides with media effect theories, such as the differential susceptibility to media effects model (Valkenburg and Peter, 2013) that summarizes different media effect theories in four theoretical assumptions. One assumption postulates that demographical and personality characteristics determine how susceptible an individual is to the impact of (social) media images. Social media imagery may appeal more to some users because of the congruence with their identity. This assumption is (partly) rooted within cognitive dissonance theory that argues that when new stimuli are congruent with one's identity, individuals are more likely to accept these stimuli and strengthen the identity ties that relate to the stimuli (Festinger, 1962). The new stimuli are regarded as a re-confirmation of existing identity structures (Festinger, 1962). With regard to risky selfies, especially developmental status, gender, sensation seeking, and narcissism may predict such congruencies and thus strengthen the links between social media, attitudinal, normative, and prototype beliefs about risky selfies, willingness to take risky selfies, and actual experiences.

First, developmental literature explains that adolescence is a key experimentation period for reckless behavior. Brain research has described that pubertal changes evoke an increased sensitivity for rewarding experiences, such as risky activities that are approved by peers (Steinberg, 2008). These changes cause a peak in adolescents' risk activities around middle adolescence (Steinberg, 2008). After this period, self-regulation skills will increase, which, in turn, cause a decline in risk taking activities in late adolescence (Steinberg, 2008). Applied to the current study, the peak in risk sensitivity in middle adolescence may imply that risky selfies are more attractive to middle adolescents than to late adolescents. That is because such risky selfies are congruent with existing heightened levels of interests in risky activities. 


\section{RISKY SELFIES AMONG ADOLESCENTS}

Second, men and boys are more attracted to risk behavior than women and girls (Arnett, 1992; Harris and Jenkins, 2006). Women potentially engage less in risk behavior because they are expected to enjoy these activities less than men (Harris and Jenkins, 2006). Gender socialization theory further adds that risk behaviors help to establish a masculine identity (De Visser and McDonnell, 2012). Accordingly, risky selfies may especially attract male adolescents as they already have favorable attitudes to general risk behavior.

Third, sensation seekers are more easily drawn to sensational and risky behaviors (e.g., Jonah, 1997). Zuckerman (2014, p. 10) defined sensation seeking as "a trait defined by the need for varied, novel, and complex sensations and experiences, and the willingness to take physical and social risks to gain such experiences". This trait especially increases during adolescence although inter-individual variations are still present (Arnett, 1992). Because sensation seekers are drawn to dangerous experiences (Arnett, 1992; Zuckerman, 2014), high levels of sensation seeking are likely to increase individuals' attraction to risky selfie behavior.

Lastly, narcissism is a key characteristic to explain photo posting behavior on social media (Ong et al., 2011). This trait typically increases during adolescence when adolescents start to develop their own identity and become more independent from their parents (Cramer, 1995). Narcissism can be characterized by "a grandiose sense of self, feelings of entitlement, and a dominant and antagonistic interpersonal style" (Gentile et al., 2013). Narcissistic adolescents are likely to show their grandiose in their online profile and they also rate their personal profile pictures as more attractive and cool compared to less narcissistic adolescents (Ong et al., 2011). Accordingly, narcissistic adolescents may be more drawn towards risky selfies compared to non-narcissistic adolescents as these selfies can help establish an original self-presentation online.

Based on this literature, we propose that gender, developmental status, sensation seeking, and narcissism moderate the links with social media use in the hypothesized model (Figure 1).

\section{Methods}

\section{Sample}




\section{RISKY SELFIES AMONG ADOLESCENTS}

A team of researchers contacted schools throughout Flanders, the Northern Dutchspeaking part of Belgium by contacting their personal network and selecting ad random schools from the list of schools of the Department of Education. A total of 10 schools agreed to participate in the study. After the educational staff was fully informed about the study aims, parents received an active parental consent form. Adolescents with active parental consent participated in the study. Researchers visited the schools and asked participants to fill in the paper-and-pencil questionnaire. Confidentiality was guaranteed. The present study was approved by the Ethical Review Committee of the KU Leuven. The data that were used for the present study were collected in the context of a larger study ${ }^{1}$.

The present study focused on middle and late adolescents given that these developmental groups are the most active social media users (Apestaartjaren, 2018) and adolescence is a fundamental period for risk behavior (Arnett, 1992). Of the 710 adolescents who filled in the survey, participants with missing values in more than $30 \%$ of the items $(N=17)$ or who indicated to have not filled in the survey honestly $(N=6)$, were deleted. One additional participant was excluded because its consecutive repeat response exceeded $30 \%$. As such, the analytical sample consisted of 686 participants (55.9\% girls). Their age ranged between 15 to 18 years and they were on average 16.41 years old $(S D=.98)$. The majority of this sample $(90.5 \%)$ was born in Belgium. One in four participants had a father $(25.3 \%)$ or a mother $(26.3 \%)$ with a university degree. The percentage of missing values in the analytical sample was $.81 \%$. Missing values were handled automatically by Mplus (see Muthén and Muthén, 2017).

\section{Measures}

The current study included several new measurement instruments regarding risky selfies. To create these measures, an in-depth review of the literature guided the creation of a first set of items for each scale. Next, two additional researchers highly experienced in social media research among adolescents reviewed and adapted the items and further ensured the wording was age appropriate. Lastly, nine adolescents individually reviewed the items and confirmed the items were interpreted as intended. To examine the factor structures of the new cognitive and behavioral willingness measures, a conjunct CFA that

\footnotetext{
${ }^{1}$ The larger project examines new media use among middle and late adolescents. More information can be obtained from the corresponding author.
} 


\section{RISKY SELFIES AMONG ADOLESCENTS}

simultaneously included risky selfie attitude, prototype perceptions, and willingness to take risky selfies was conducted.

Demographic variables. Gender $(0=$ boy, $1=$ girl) and age (which was a continuous variable but recoded for multiple-group analysis: $0=$ middle adolescents 15 to 16 years old, $N=331,1=$ late adolescents 17 to 18 years old, $N=332$ ) were questioned.

Sensation seeking. The 8-item short form of the Sensation Seeking Scale (Hoyle et al., 2002) was used to assess sensation seeking levels. On a 7-point Likert scale ranging from completely disagree (1) to completely agree (7), the participants rated eight items, such as "I like to do frightening things". As suggested by Hoyle et al. (2002), four estimates were produced by averaging the items in four sub-factors: boredom susceptibility $(r=.30)$, disinhibition $(r=.49)$, experience seeking $(r=.30)$, and thrill and adventure seeking $(r$ $=.46$ ). The four sub-factor estimates formed a latent variable that was used in the analyses.

Narcissism. The 13-item version of the Narcissism Personality Inventory (NPI-13; Gentile et al., 2013) was consulted. Items are rated on a forced-choice basis, such that one choice represents narcissism and the other does not (e.g., "I will usually show off if I get the chance versus I try not to be a show off') ( $\alpha=.69)$. By summing the item scores, an estimate of adolescents' narcissism was created.

Social media use. The participants completed eight questions about their time spent on the following social media platforms: Facebook, Instagram, Snapchat, and YouTube. On a 10-point Likert scale, they estimated how much time they spent on each platform on a regular weekday (Monday-Friday) and a weekend day (Saturday-Sunday). Answer options ranged from 0 hours $(0)$ to the platform is opened throughout the day continuously (10). An exploratory factor analysis (EFA) showed that the factor loadings of the two YouTube items were lower than .4. These two items were omitted. A weighted score of the average daily time for each social media platform was computed as follows: (time weekday $\times 5+$ time weekend day $\times 2$ ) / 7. Additionally, social media use was computed by the average score of the three remaining platforms.

Descriptive norms. Following Ajzen (2006), participants estimated how many of their friends post risky selfies on a 5-point Likert scale ranging from nobody (1) to everybody (5). To prevent social desirability bias, the label "exciting selfies" was used instead of 


\section{RISKY SELFIES AMONG ADOLESCENTS}

risky selfies. Exciting selfies were described as pictures that you take of yourself or that friends take of you (possibly pictures from you and your friends together) on exciting locations, such as on the roof of a high building, near a railway, on top of a remote cliff with a steep drop, or somewhere where it is not allowed to go, and during activities that require one's attention, such as driving a motorcycle or bicycle.

Subjective norms. Following Ajzen (2006), participants estimated how many of their friends approve posting exciting selfies on a 5-point Likert scale ranging from nobody (1) to everybody (5).

Attitudes. To measure participants' risky selfie attitudes, a 5-item scale was developed inspired by Ajzen (2006). We focused on one attitudinal component in line with prior literature, namely perceptions of danger (Gibbons et al., 1998). The items were formulated as follows: "I think it is dangerous to take a selfie ... a) on the roof of a high building, b) near a railway, c) on top of a remote cliff with a steep drop, d) somewhere where it is not allowed to go and e) during activities that require one's attention, such as the driving of a motorcycle or bicycle". Participants rated the items on a 7-point Likert scale ranging from I completely disagree (1) to I completely agree (7). The validity and reliability of this self-developed scale was measured with a two-step approach. First, we randomly divided the sample in two subsamples and conducted an EFA with one half of the sample $(N=343)$. Using principal axis factoring, a one-factor solution was obtained that accounted for $47.52 \%$ of the total variance with an eigenvalue of 2.38 . The factor loadings of the five items were satisfactory, ranging between .50 and $.80(\alpha=.81)$. Second, a conjunct confirmatory factor analysis (CFA) with the other half of the sample $(N=343)$ confirmed the one factor model (see the description of the willingness variable for the results). Next, all items were reversed scored and a risky selfie attitude variable was created by averaging the item scores. A higher score on this variable indicates that taking risky selfies is believed to be less dangerous.

Prototype perceptions. Following the prototypes literature (Gibbons and Gerrard, 1995; van Oosten et al., 2017), traits were selected to be evaluated on a 7-point Likert scale (1 = completely disagree, 7 = completely agree) for how typical they were for someone who regularly posts exciting selfies. The characteristics were "cool", "popular", "interesting", and "attractive". The validity and reliability of this scale was again examined by the twostep approach. First, an EFA obtained a one-factor solution that accounted for $69.51 \%$ of the total variance with an eigenvalue of 2.78. The factor loadings for the four items 


\section{RISKY SELFIES AMONG ADOLESCENTS}

ranged from .76 and $.88(\alpha=.89)$. Next, a conjunct CFA confirmed the one factor model of prototype perceptions (see the description of the willingness variable for the results). By averaging the item scores, a prototype variable was created. A higher score indicates a more positive prototype perception.

Willingness. Following prototypes literature (Gibbons and Gerrard, 1995), participants evaluated their willingness to engage in risky selfie behavior in three situations: (1) "You are near a remote railway and your friends dare you to take a selfie when you are on the railway", (2) "You are on a holiday and you could take a selfie while jumping off a cliff into a lake. A "no jumping" sign is present, though, you believe that the lake will be deep enough to safely jump. You climb the cliff and jump into the lake to take the selfie" and (3) "You are riding your bicycle with your friends and you would like to take a selfie while you are riding the bicycle. You think you can manage such a behavior, so you take the selfie".

Participants used a 5-point Likert scale ranging from not likely at all (1) to highly likely (5). The validity and reliability of this scale was again examined by the two-step approach. A one-factor solution was obtained from the EFA that accounted for $37.60 \%$ of the total variance with an eigenvalue of 1.13. The factor loadings for the three items that assessed willingness $(\alpha=.66)$ were ranging between .54 and .67 . Next, a conjunct CFA validated the one factor structure of willingness. This conjunct CFA examined the factors of attitudes, prototype perceptions, and willingness and had an admissible fit $\chi^{2}=153.74$, degrees of freedom $[d f]=51, p<.001$; comparative fit index $[\mathrm{CFI}]=.937$; root mean square error approximation $[\mathrm{RMSEA}]=.077 ; \chi^{2} / d f=3.01$ ). By averaging the item scores, a willingness variable was created. A higher score on this variable indicates a greater willingness to take a risky selfie.

Risky selfie behavior. Participants' own experience with taking risky selfies was measured with one item "To what extent do you have experience with taking exciting selfies?" on a 4-point Likert-scale ( 1 = no experience, 4 = much experience).

\section{Analyses}

Descriptive statistics were examined. The hypothesized relations were tested with structural equation modeling (Mplus) (figure 1). Age, gender, sensation seeking, and narcissism were included as covariates. Error terms of covariates were correlated. 


\section{RISKY SELFIES AMONG ADOLESCENTS}

Similarly, social media use was correlated with the included covariates. To test for

mediation effects, 5000 bootstrapped samples were estimated to obtain the $95 \%$ biascorrected (BC) confidence intervals (CIs). Values higher than .95 for the CFI and values lower than .06 for the RMSEA are considered a good fit of the model (Hu and Bentler, 1999).

Gender (boys vs girls) and developmental status (middle vs late adolescents) differences were evaluated using Mplus multiple-group analysis. First, measurement invariance tests for risky selfie attitudes, prototype perceptions, and willingness were conducted to test whether the factor loadings of the measurements are the same for the groups (middle vs late adolescents and boys vs girls) (Meredith, 1993). The configural model, in which we imposed no equality constraints on the factor loadings of the variables in each group, served as our baseline model. This model was compared with a model in which all factor loadings were constrained to be equal across developmental status (age) or gender. The CFI difference test $(\triangle \mathrm{CFI})$ was used as an indicator of measurement invariance in the multiple-group comparisons. A $\Delta$ CFI higher than .01 indicates a meaningful change in model fit and thus differences between groups with regard to the factor loadings of the variables (Cheung and Rensvold, 2002). Second, path invariance was tested. Configural SEM models, in which all path coefficients were set free across the targeted groups were compared to SEM models in which the hypothesized links with social media use were set invariant across groups. The variance-adjusted chisquare test statistics of both models, obtained by using maximum likelihood with missing values (MLMV) as estimator, were compared (Muthén and Muthén, 2017). A $\Delta \chi^{2}$ MLMV with a p-value lower than .05 indicates differences between compared groups with regard to the hypothesized paths with social media use.

To test the other hypothesized moderation effects, interaction terms for sensation seeking and narcissism were created. Different procedures were used to create these terms as sensation seeking is treated in the present study as a latent variable and narcissism is modeled as a manifest variable given the dichotomous nature of its scale items. Regarding sensation seeking, a latent interaction term was produced by multiplying the latent variable of sensation seeking and the manifest social media use variable. This interaction term was included in the model simultaneously with the latent sensation seeking variable and the manifest social media use variable. This Mplus procedure is valid even when multicollinearity would be a problem. Regarding narcissism, a manifest interaction term was generated by multiplying the manifest narcissism variable 


\section{RISKY SELFIES AMONG ADOLESCENTS}

(the standardized $Z$ scores: $Z$ ) with the manifest social media use variable $(Z)$. Also, this interaction term was included in the model together with narcissism $(Z)$ and social media use (Z). Multicollinearity was no problem as VIF-values were below 5.

\section{Results}

\section{Descriptive Statistics}

The results showed that adolescents spent on average 1.5 hours daily on social media. Adolescents further reported that less than half of their friends had posted risky selfies (descriptive norms), and that about half of their friends approved such pictures (subjective norms) (see Table 1 for $M$ 's and $S D^{\prime}$ 's). The mean level of attitudes indicated that adolescents did not particularly consider risky selfie taking as "risky". Adolescents' prototype perceptions were rather negative. Adolescents further reported to be somewhat unwilling to take such selfies. Furthermore, on average, adolescents had limited risky selfie taking experience. A percentile distribution further informed that $9.2 \%$ of the participants had much experience, that $23.7 \%$ had some experience, and that $32.5 \%$ and $34.6 \%$ had not much to no experience. Zero-order inter-correlations among the key variables are also presented in Table 1 . Almost all correlations were significant $(p<.05)$.

[Table 1.]

\section{Hypothesized Model}

The tested model showed an acceptable fit $\left(\chi^{2}=649.51, d f=182, p<.001\right.$; RMSEA $\left.=.061 ; \mathrm{CFI}=.906 ; \chi^{2} / d f=3.57\right)$. First, the results showed that social media use positively predicted descriptive norms and prototype perceptions. No support emerged for significant relations between social media use and subjective norms or attitudes $(p>.05)$ (see Figure 2 for parameter values).

Second, the results demonstrated that attitudes and prototype perceptions were positively related to willingness. No significant relations emerged between (descriptive/subjective) norms and willingness. Furthermore, willingness positively predicted risky selfie behavior. Together, all predictors in the model explained $33 \%$ of the variance in risky selfie behavior $\left(R^{2}=.33\right)$. 


\section{RISKY SELFIES AMONG ADOLESCENTS}

\section{[Figure 2.]}

Significant indirect paths were found between social media use and risky selfie taking through prototype perceptions and willingness $(\beta=.012, B=.006, S E=.003, p$ $=.063,95 \%$ CI: .001/.014). No other significant indirect paths emerged. A significant direct path emerged between social media use and risky selfie behavior.

\section{Moderation Tests of Gender and Age}

Measurement Invariance. To test the equivalence of the measurement models of attitudes, prototype perceptions, and willingness across gender and age groups, the configural model, in which we imposed no equality constraints between groups, served as our baseline model. This model was compared with a model in which all factor loadings were constrained to be equal across gender or age. The results showed no differences between the constrained model (model fit gender: $\chi^{2}=395.92, d f=111, p<.001$; RMSEA $=.088 ; \mathrm{CFI}=.913 ; \chi^{2} / d f=3.57$; model fit age: $\chi^{2}=383.95, d f=111, p<.001$; RMSEA $=.087 ; \mathrm{CFI}=.915 ; \chi^{2} / d f=3.46$ ) and the configural model (model fit gender: $\chi^{2}$ $=371.05, d f=102, p<.001 ; \mathrm{RMSEA}=.090 ; \mathrm{CFI}=.918 ; \chi^{2} / d f=3.64$; model fit age: $\chi^{2}=$ $\left.374.23, d f=102, p<.001 ; \mathrm{RMSEA}=.091 ; \mathrm{CFI}=.915 ; \chi^{2} / d f=3.67\right)$ for both gender $\left(\Delta \chi^{2}\right.$ $=24.87, \Delta d f=9, p<.01 ; \Delta \mathrm{CFI}=-.005$, the value was lower than .01$)$ and age $\left(\Delta \chi^{2}=\right.$ $9.72, \Delta d f=9, p>.05 ; \Delta \mathrm{CFI}=.000)$ groups, which indicated that the factor loadings were the same for boys versus girls and middle versus late adolescents.

Path invariance. The conducted moderation tests between the restricted model (model fit gender: $\chi^{2}=624.97, d f=370, p<.001 ; \mathrm{RMSEA}=.047 ; \mathrm{CFI}=.904 ; \chi^{2} / d f=$ 1.69; model fit age: $\chi^{2}=638.71, d f=370, p<.001$; RMSEA $=.048 ; \mathrm{CFI}=.901 ; \chi^{2} / d f=$ 1.73 ) and the configural SEM model (model fit gender: $\chi^{2}=620.00, d f=364, p<.001$; RMSEA $=.047 ;$ CFI $=.904 ; \chi^{2} / d f=1.70$; model fit age: $\chi^{2}=633.84, d f=364, p<.001$; $\left.\mathrm{RMSEA}=.049 ; \mathrm{CFI}=.901 ; \chi^{2} / d f=1.74\right)$ showed that the hypothesized pathways with social media remained invariant across gender $\left(\Delta \chi_{\text {MLMV }}^{2}=5.25, \Delta d f=6, p>.05\right)$ and age $\left(\Delta \chi_{\text {MLMV }}^{2}=5.24, \Delta d f=6, p>.05\right)$. That is, gender and age did not significantly moderate the hypothesized paths with social media.

\section{Moderation Tests of Sensation Seeking and Narcissism}




\section{RISKY SELFIES AMONG ADOLESCENTS}

There were no significant interaction effects (all $p>.05$ ) between sensation seeking and social media use on descriptive norms $(B=.06, S E=.05)$; subjective norms $(B=.04, S E$ $=.05, p>.05)$; attitudes $(B=-.01, S E=.05)$; prototype perceptions $(B=-.03, S E=.05)$; willingness $(B=-.02, S E=.04)$; and behavior $(B=-.03, S E=.04)$.

Likewise, there were no significant interaction effects (all $p>.05$ ) between narcissism and social media use on descriptive norms $(B=.06, S E=.03)$; subjective norms $(B=.06, S E=.04)$; attitudes $(B=.03, S E=.04)$; prototype perceptions $(B=-.03$, $S E=.05)$; willingness $(B=.001, S E=.03)$; and behavior $(B=-.01, S E=.03)$.

\section{Discussion}

The current study is the first empirical study on adolescents' risky selfie behavior and explained this behavior from a prototype willingness model perspective. Our results showed that social media use related to adolescents' descriptive norms, prototype perceptions, and risky selfie behavior. Attitudes and prototype perceptions were further found to relate to adolescents' willingness to take risky selfies and their actual risky selfie behavior. These results have several implications.

\section{Concerns on Risky Selfie Behavior}

The current study responded to concerns that have arisen in the public and scholarly discourse concerning risky selfies (Ayeh, 2018; Lamba et al., 2016). The study data were the first to examine this behavior among social media users and underline the validity of these concerns to some extent among adolescents. Approximately $65 \%$ has at least once taken a risky selfie and one in three adolescents indicated to have some to substantial experience with this risk behavior. Our correlational data further showed that the personality characteristics narcissism and sensation seeking positively correlated with the taking of risky selfies. Future research may further examine the links between identity markers and risky selfie behavior, and explore other relevant factors, such as self-esteem (Veselska et al., 2009) or family bounds (Tyler, 2008).

\section{The Value of the Prototype Willingness Model to Explain Risky}

\section{Selfie Behavior}




\section{RISKY SELFIES AMONG ADOLESCENTS}

The results coincide with past research showing social media use is positively related to adolescent online risk behavior (e.g., Festl and Quandt, 2016). Explanatory processes theorized in the PWM further proved to be partly valid to explain this relation, though, some inconsistent findings also occurred. Therefore, our data underline the partly mixed conclusion of recent studies on the validity of the PWM model to explain online risk behavior next to offline risk behavior (Walrave et al., 2015).

Within the inconsistent findings, the results firstly did not support a significant link between social media use and subjective norms. Social media appear to be a venue for adolescents to learn about their peers' risk behavior (i.e., descriptive norms), but not to learn about the approval of (close) peers of those behaviors. This finding is surprising as a major aspect of social media interactions is approving each other's content in the form of likes and comments (Zell and Moeller, 2018). However, adolescents are known to like almost all social media content of their (close) friends; they even explicitly ask each other to like a post when they have not done this yet (Yau and Reich, 2018). As a result, all sorts of social media content gets likes. Likes are even perceived by adolescents as something that is "commonplace" (Yau and Reich, 2018). Moreover, positive comments seem more accepted, and therefore more prevalent, on social media than negative ones (Ziegele and Reinecke, 2017). Similar to other social media content, risky selfies may receive likes and positive comments, but it might remain unclear for an adolescent whether his/her peers truly approve of this specific behavior and whether they thus positively respond "out of habit". Therefore, subjective norms are potentially not developed in social media interactions, but rather during interpersonal interactions, as peers may here be more straightforward in their (dis)approval of such behaviors. Future research is needed to further examine this explanation.

Additionally, the findings showed full support for the social reaction path (i.e., prototype perceptions predicted willingness/behavior), but only moderate support was found for the reasoned path of the PWM. Neither descriptive norms nor subjective norms predicted willingness. Similar results have been found in the study of Van Gool and colleagues (2015) in which no significant association between social norms and willingness to disclose personal information on Facebook emerged (Van Gool et al., 2015). As suggested by Kallgren et al. (2000), social norms may not constantly drive individuals' behavior. Potentially, the taking of risky selfies is one of these behaviors and future research seems warranted to fully exclude the normative influence on this particular selfie behavior. 


\section{RISKY SELFIES AMONG ADOLESCENTS}

Among the reasoned path, attitudes did occur as an important determinant of adolescents' risky selfie behavior. The less dangerous adolescents think it was to take risky selfies, the more willing they were to take such selfies themselves. Yet, their attitudes were not affected by social media use. As the descriptive data indicated that adolescents did not particularly consider the taking of risky selfies as "risky", interventions may find this a useful variable as there seems to be room in heightening adolescents' awareness on the risks of such selfies. However, it is possible that adolescents who perceive risky selfie taking to be dangerous, not necessarily evaluate this behavior as negative. As adolescents are well-known risk seekers, they may even favor risky and thus dangerous activities. Future research should take this notion into account and explore which other attitudinal components, apart from perceptions of danger, negatively predict risky selfie- taking behavior. The knowledge that will follow from such research lines will help shape the messages of future intervention studies.

Next to attitudes, prototype perceptions appeared as a valid mechanism to explain risky selfie behavior. This finding coincides with studies reporting similar conclusions (e.g., Walrave et al., 2015). However, it should be noted that the prototype perceptions were rather negative in the current sample of adolescents. It would be interesting to further examine whether prototype perceptions of risky selfie takers are also affected by other factors than social media use. For instance, during (offline) family conversations, parents may comment negatively on risky selfie takers and, as such, adolescents may develop more negative prototype perceptions (Collier et al., 2016). Moreover, we only included four indicators of prototype perceptions. Future research may include other indicators of prototype perceptions (e.g., smart) that potentially are more relevant for a favorable view towards the typical risky selfie taker.

Lastly, a direct relation emerged between social media use and risky selfie taking suggesting other mediators except those suggested in PWM are relevant. Future research may consider other theories, such as wishful identification theory (Hoffner, 1996), to introduce additional mediators that help explain why adolescents engage in risky selfie behavior.

\section{Individual Susceptibility Variables}

The current study showed that neither gender, age, sensation seeking, nor narcissism moderated the studied relations with social media use. As noted above, our descriptive 


\section{RISKY SELFIES AMONG ADOLESCENTS}

data did indicate the relevance of several of the targeted individual susceptibility variables to determine how adolescents think about risky selfies (cognitive factors) and engage themselves into taking risky selfies (willingness and behavior). However, we could not find that social media use affects such cognitions or behaviors differently depending on gender, age, sensation seeking, or narcissism, even though current media effect theories point at the conditional relevance of such dispositional factors (e.g., Valkenburg and Peter, 2013).

One possible explanation might relate to our measure of social media use. These media effect theories specifically argue that the congruence between specific content types (e.g., risky selfies on social media) and dispositional factors (e.g., being a sensation seeker) may enhance the effects of this content (e.g., Valkenburg and Peter, 2013). It is therefore possible that such congruence effects were not captured as social media use in general was measured and not specific exposure to risky selfies on social media.

Another explanation may be that we did not take into account additional complexities that surround each of the included dispositional factors. For instance, most of the selfies that social media users take are not uploaded on social media (Katz and Crocker, 2015). Narcissists are likely to care less about their personal pictures and more about the pictures that are posted of themselves online (Etgar and Amichai-Hamburger, 2017). Accordingly, research particularly focusing on the posting of risky selfies online and not on the general act of taking risky selfies as we did in the current study might find different results.

Finally, other variables could prove relevant to consider as moderators for the links with social media use. For example, in prior studies, social comparison tendencies (Gibbons and Gerrard, 1995) and need for popularity (Walrave et al., 2015) were suggested as moderators for links in the PWM.

\section{Limitations}

The current study has shortcomings, which could open avenues for future research. First, the study was limited because of its cross-sectional design. Future longitudinal studies should further explore the proposed causal order in our model on risky selfies. Second, our study was the first study to develop several measures on risky selfies. Future research may further examine the reliability and validity of the newly developed measurement 


\section{RISKY SELFIES AMONG ADOLESCENTS}

instruments, especially the three-item willingness scale as the Cronbach's alpha was below .7 $(\alpha=.66)$. This measure might have influenced the fit of the model, which could be perceived as sub-optimal as the values of the fit indices were somewhat higher (RMSEA) or lower (CFI) than the cutoff values that are described in the literature $(\mathrm{Hu}$ and Bentler, 1999). Although somewhat higher or lower values are not uncommon and are accepted in (media effect) research that explains adolescent risk behavior (e.g., Pabian et al., 2015), future research should take into account the weaknesses regarding some of the measures of the present study in order to improve model fit.

Related to this, the current study was conducted in the context of a Western European country. The generalizability of the study findings to other cultural contexts is therefore limited as research has suggested to consider culture when exploring social media interactions (Livingstone, 2014) and adolescents' risk taking behaviors in general (Kloep et al., 2009). Therefore, follow-up studies across different cultures seem highly valuable and necessary.

Next, the intention to perform the risk behavior, which is part of the reasoned pathway of the PWM and which is expected to be explained by attitudes and norms, was not included. In this way, the PWM was only partially tested. Intention was omitted following other recent studies that rely on the PWM (e.g., van Oosten, et al., 2017). In accordance to these studies, attitudes and norms were expected to predict willingness. Also the original PWM model describes that the reasoned and the social reaction pathway are connected and that the reasoned constructs not only affect the intention to perform the behavior, but also behavioral willingness (Gerrard et al., 2008). Future research may test the full PWM model by including the intention to take risky selfies to investigate whether the relations between the constructs are the same when intention is taken into account.

Finally, we used a general measure of social media use and did not address exposure to risky selfies in particular. Findings from prior studies (e.g., Sargent et al., 2007) underline that such detailed measurement instruments may be necessary to fully capture the examined media effects. As our results were the first to show that a considerable number of adolescents has some experience with taking risky selfies, it is probable that such selfies appear every so often on one's social media feed. Though, important variations in exposure may exist across adolescents as each social media feed depends on "a complex interaction between friending choices, the content those "friends" post, and opaque algorithms that display some content over others" (Vraga et al., 2016, p. 


\section{RISKY SELFIES AMONG ADOLESCENTS}

150). We thus strongly advice follow-up studies on this topic to include detailed measures of risky selfies exposure or to use other research designs, such as experiments.

\section{Conclusion}

The current study was the first to examine the links between social media use and adolescents' risky selfie behavior and showed the partial validity of the prototype willingness model to explain such relations. More precisely, prototype perceptions emerged as a relevant mediator which needs to be considered in future research. No support was found for the moderating roles of gender, developmental status, narcissism, and sensation seeking in relation with social media use. Given the prevalence of risky selfie behavior among adolescents, more research seems needed on why adolescents become online daredevils.

\section{Funding}

This research received no specific grant from any funding agency in the public, commercial, or not-for-profit sectors.

\section{Declaration of conflicting interests}

The authors declare that there is no conflict of interest. 


\section{RISKY SELFIES AMONG ADOLESCENTS}

\section{References}

Ajzen I (2006) Constructing a TPB questionnaire: Conceptual and methodological considerations. Available at:

http://www.people.umass.edu/aizen/pdf/tpb.measurement.pdf.

Anderson M and Jiang J (2018) Teens, social media and technology 2018. Report, Pew Research Center, May. Retrived from:

https://www.pewinternet.org/2018/05/31/teens-social-media-technology-2018/

Apestaartjaren (2018) Research rapport Apestaartjaren 7. Report, Gent: Mediaraven and Mediawijs, May. Retrived from: https://www.apestaartjaren.be/

Arnett J (1992) Reckless Behavior in Adolescence: A Developmental Perspective. Developmental Review 12(4): 339-373.

Ayeh JK (2018) Distracted gaze: Problematic use of mobile technologies in vacation contexts. Tourism Management Perspectives 26: 31-38.

Cheung GW and Rensvold RB (2002) Evaluating Goodness-of-Fit Indexes for Testing Measurement Invariance. Structural Equation Modeling 9(2): 233-255.

Collier KM, Coyne SM, Rasmussen EE, et al. (2016) Does parental mediation of media influence child outcomes? A meta-analysis on media time, aggression, substance use, and sexual behavior. Developmental Psychology 52(5): 798-812. 


\section{RISKY SELFIES AMONG ADOLESCENTS}

Cramer P (1995) Identity, narcissism, and defence mechanisms in late adolescence. Journal of Research in Personality 29(3): 341-361.

De Visser RO and Mcdonnell E (2012) 'That's OK. He's a guy': A mixed-methods study of gender double-standards for alcohol use. Psychology \& Health 27(5): 618-639.

Etgar S and Amichaihamburger Y (2017) Not all selfies took alike: Distinct selfie motivations are related to different personality characteristics. Frontiers in Psychology 8: 842.

Festinger L (1962) A theory of cognitive dissonance. Palo Alto, CA: Stanford University Press.

Festl R and Quandt T (2016) The role of online communication in long-term cyberbullying involvement among girls and boys. Journal of Youth and Adolescence 45(9): 1931-1945.

Flaherty G and Choi J (2016) The 'selfie' phenomenon: reducing the risk of harm while using smartphones during international travel. Journal of Travel Medicine 23(2): $\operatorname{tav} 026$.

Gentile B, Miller JD, Hoffman BJ, et al. (2013) A test of two brief measures of grandiose narcissism: the narcissistic personality inventory-13 and the narcissistic personality inventory-16. Psychological Assessment 25(4): 1120-1136. 


\section{RISKY SELFIES AMONG ADOLESCENTS}

Gerrard M, Gibbons FX, Houlihan AE, et al. (2008) A dual-process approach to health risk decision making: The prototype willingness model. Developmental Review 28(1): 29-61.

Gibbons FX and Gerrard M (1995) Predicting young adults' health risk behavior. Journal of Personality and Social Psychology 69(3): 505-517.

Gibbons FX, Gerrard M, Blanton H and Russell DW (1998) Reasoned Action and Social Reaction: Willingness and Intention as Independent Predictors of Health Risk. Journal of Personality and Social Psychology 74: 1164-1180.

Harris CR, Jenkins M and Glaser D (2006) Gender differences in risk assessment: Why do women take fewer risks than men? Judgment and Decision Making 1(1): 48-63.

Hoffner C (1996) Children's wishful identification and parasocial interaction with favorite television characters. Journal of Broadcasting and Electronic Media 40: $389-402$.

Hoyle RH, Stephenson MT, Palmgreen P, et al. (2002) Reliability and validity of a brief measure of sensation seeking. Personality and Individual Differences 32(3): 401-414.

Hu L and Bentler PM (1999) Cutoff criteria for fit indexes in covariance structure analysis: Conventional criteria versus new alternatives. Structural Equation Modeling 6(1): 1-55.

Jonah BA (1997) Sensation seeking and risky driving: A review and synthesis of the literature. Accident Analysis \& Prevention 29(5): 651-665. 


\section{RISKY SELFIES AMONG ADOLESCENTS}

Kallgren CA, Reno RR and Cialdini RB (2000) A focus theory of normative conduct: When norms do and do not affect behavior. Personality and Social Psychology Bulletin 26(8): 1002-1012.

Katz JE and Crocker ET (2015) Selfies| selfies and photo messaging as visual conversation: Reports from the United States, United Kingdom and China. International Journal of Communication 9: 1861-1872.

Kloep M, Güney N, Çok F and Simsek ÖF (2009) Motives for risk-taking in adolescence: A cross-cultural study. Journal of Adolescence 32(1): 135-151.

Lamba H, Bharadhwaj V, Vachher M, et al. (2016) Me, myself and my killfie: Characterizing and preventing selfie deaths. Available at: https://arxiv.org/abs/1611.01911

Livingstone S (2014) Developing social media literacy: How children learn to interpret risky opportunities on social network sites. Communications 39(3): 283-303.

Meredith W (1993) Measurement invariance, factor analysis and factorial invariance. Psychometrika 58(4): 525-543.

Muthén LK and Muthén BO (2017) Mplus user's guide. Eighth edition. Los Angeles, CA: Muthén \& Muthén.

Nowland R, Necka EA and Cacioppo JT (2018) Loneliness and social internet use: Pathways to reconnection in a digital world? Perspectives on Psychological Science 13(1): 70-87. 


\section{RISKY SELFIES AMONG ADOLESCENTS}

Ong EYL, Ang RP, Ho JCM, et al. (2011) Narcissism, extraversion and adolescents' selfpresentation on Facebook. Personality and Individual Differences 50(2): 180-185.

Pabian S, De Backer CJS and Vandebosch H (2015) Dark triad personality traits and adolescent cyber-aggression. Personality and Individual Differences 75: 41-46.

Peluchette JV and Karl KA (2009) Examining students' intended image on Facebook: “What were they thinking?!". The Journal of Education for Business 85(1): 30-37.

Priceonomics (2016) The tragic data behind selfie facilities. Available at: https://priceonomics.com/the-tragic-data-behind-selfie-fatalities.

Reinecke L and Trepte S (2014) Authenticity and well-being on social network sites: A two-wave longitudinal study on the effects of online authenticity and the positivity bias in SNS communication. Computers in Human Behavior 30: 95-102.

Romanos A (2015) Trolltunga photos removed after fatal fall. news.com.au, 10 September. Available at: https://www.news.com.au/world/breaking-news/trolltungaphotos-removed-after-fatal-fall/news-story/c8bf56555aa9f9c28c52ee69c4a515b5

Sargent JD, Stoolmiller M, Worth KA, et al. (2007) Exposure to smoking depictions in movies its association with established adolescent smoking. JAMA Pediatrics 161(9): 849-856.

Steinberg L (2008) A social neuroscience perspective on adolescent risk-taking. Developmental Review 28(1): 78-106. 


\section{RISKY SELFIES AMONG ADOLESCENTS}

Subrahmanyam K and Šmahel D (2011) Digital youth: The role of media in development. New York, NY: Springer.

Sung Y, Lee J, Kim E, et al. (2016) Why we post selfies: Understanding motivations for posting pictures of oneself. Personality and Individual Differences 97: 260-265.

Tyler KA (2008) Social network characteristics and risky sexual and drug related behaviors among homeless young adults. Social Science Research 37(2): 673-685.

Valkenburg PM and Peter J (2013) The differential susceptibility to media effects model. Journal of Communication 63(2): 221-243.

Van Gool E, Van Ouytsel J, Ponnet K, et al. (2015) To share or not to share? Adolescents' self-disclosure about peer relationships on Facebook: An application of the Prototype Willingness Model. Computers in Human Behavior 44: 230-239.

van Oosten JMF, Peter J and Vandenbosch L (2017) Adolescents' sexual media use and willingness to engage in casual sex: Differential relations and underlying processes. Human Communication Research 43(1): 127-147.

Veselska ZD, Geckova AM, Orosova O, et al. (2009) Self-esteem and resilience: The connection with risky behavior among adolescents. Addictive Behaviors 34(3): 287291.

Vraga E, Bode L and Troller-Renfree S (2016) Beyond self-reports: Using eye tracking to measure topic and style differences in attention to social media content, Communication Methods and Measures 10:149-164. 


\section{RISKY SELFIES AMONG ADOLESCENTS}

Walrave M, Ponnet K, Van Ouytsel J, et al. (2015) Whether or not to engage in sexting. Explaining adolescent sexting behavior by applying the prototype willingness model. Telematics and Informatics 32(4): 796-808.

Wang D, Park S and Fesenmaier DR (2012) The role of smartphones in mediating the touristic experience. Journal of Travel Research 51(4): 371-387.

Yau JC and Reich SM (2018) "It's just a lot of work": Adolescents' self-presentation norms and practices on Facebook and Instagram. Journal of Research on Adolescence 29(1): 1-14.

Zell AL and Moeller L (2018) Are you happy for me ... on Facebook? The potential importance of "likes" and comments. Computers in Human Behavior 78: 26-33.

Ziegele M and Reinecke L (2017) No place for negative emotions? The effects of message valence, communication channel, and social distance on users' willingness to respond to SNS status updates. Computers in Human Behavior 75: 704-713.

Zuckerman M (2014) Sensation seeking (psychology revivals): Beyond the optimal level of arousal. New York, NY: Psychology Press. 


\section{RISKY SELFIES AMONG ADOLESCENTS}

Author biographies

Shuang Chen is an assistant professor at the School of Media, University of Chinese Academy of Social Sciences. Her research interests include the psychological impact of social media, emotions and information diffusion microblog. She now specifically focuses on the relations between adolescents and emerging adults social media use and wellbeing.

Lara Schreurs is a PhD Fellow of the Research Foundation Flanders (FWO) at the Leuven School for Mass Communication Research (KU Leuven) under supervision of Professor Laura Vandenbosch. Her research interests concern the relations between adolescents' and young adults' (social) media use and wellbeing. In her PhD-project, Lara specifically focuses on the role of social media literacy within the social mediaeffects literature.

Sara Pabian (Ph.D.) is a halftime assistant professor and halftime postdoc researcher at the research group MIOS (Media, ICT, and Interpersonal Relations In Organisations and Society), University of Antwerp. The focus of her research is on media use and (online) aggression. Her research is currently funded by the Research Foundation Flanders (FWO). The results of her research are published in international journals within the fields of communication, social psychology, developmental psychology, behavioral development and sociology.

Laura Vandenbosch is an assistant professor at the School for Mass Communication Research (BOF-ZAP research professorship grant), KU Leuven. The relations between media and wellbeing is the core subject of her research, leading to international publications in several fields including developmental psychology, sexology, body image, social relationships and communication theory. 


\section{RISKY SELFIES AMONG ADOLESCENTS}

Table 1. Zero-Order Inter-Correlations, Means, SDs and Ranges.

\begin{tabular}{|c|c|c|c|c|c|c|c|c|c|c|c|c|c|c|}
\hline & 1 & 2 & 3 & 4 & 5 & 6 & 7 & 8 & 9 & 10 & 11 & $M$ & $S D$ & Range \\
\hline 1. Gender & 1 & & & & & & & & & & & - & - & - \\
\hline 2. Age & $-.08^{*}$ & 1 & & & & & & & & & & 16.41 & .98 & $15-18$ \\
\hline 3. Narcissism & $-.20^{* * *}$ & $.09^{*}$ & 1 & & & & & & & & & 3.36 & 2.56 & $0-12$ \\
\hline 4. Sensation seeking & -.03 & .04 & $.22^{* * *}$ & 1 & & & & & & & & 4.58 & .99 & $1.38-7$ \\
\hline 5. Social media use & $.23^{* * *}$ & $-.12^{* *}$ & $.12^{* *}$ & $.16^{* * *}$ & 1 & & & & & & & 3.96 & 2.05 & $1-10$ \\
\hline 6. Risky selfie descriptive norms & -.02 & $-.15^{* * *}$ & .05 & $.10^{*}$ & $.19^{* * *}$ & 1 & & & & & & 2.31 & .90 & $1-5$ \\
\hline 7. Risky selfie subjective norms & .02 & $-.08^{*}$ & .04 & $.09^{*}$ & .06 & $.50^{* * *}$ & 1 & & & & & 2.68 & .98 & $1-5$ \\
\hline 8. Risky selfie attitudes & $-.18^{* * *}$ & -.01 & $.15^{* * *}$ & $.31^{* * *}$ & $.13^{* * *}$ & $.16^{* * *}$ & $.15^{* * *}$ & 1 & & & & 3.61 & 1.15 & $1-7$ \\
\hline 9. Risky selfie prototype perceptions & .01 & -.04 & $.15^{* * * *}$ & $.16^{* * *}$ & $.21^{* * *}$ & $.13^{* *}$ & $.22^{* * *}$ & $.09^{*}$ & 1 & & & 2.94 & 1.27 & $1-6$ \\
\hline 10. Risky selfie willingness & -.03 & -.07 & $.16^{* * * *}$ & $.44^{* * * *}$ & $.24^{* * * *}$ & $.14^{* * *}$ & $.15^{* * *}$ & $.40^{* * *}$ & $.34^{* * *}$ & 1 & & 2.51 & .94 & $1-5$ \\
\hline 11. Risky selfie behavior & -.06 & -.03 & $.23^{* * *}$ & $.38^{* * *}$ & $.26^{* * *}$ & $.20^{* * *}$ & $.19^{* * *}$ & $.31^{* * *}$ & $.27^{* * *}$ & $.42^{* * *}$ & 1 & 2.08 & .97 & $1-4$ \\
\hline
\end{tabular}

Note. ${ }^{*} p<.05,{ }^{* *} p<.01,{ }^{* * *} p<.001$. 


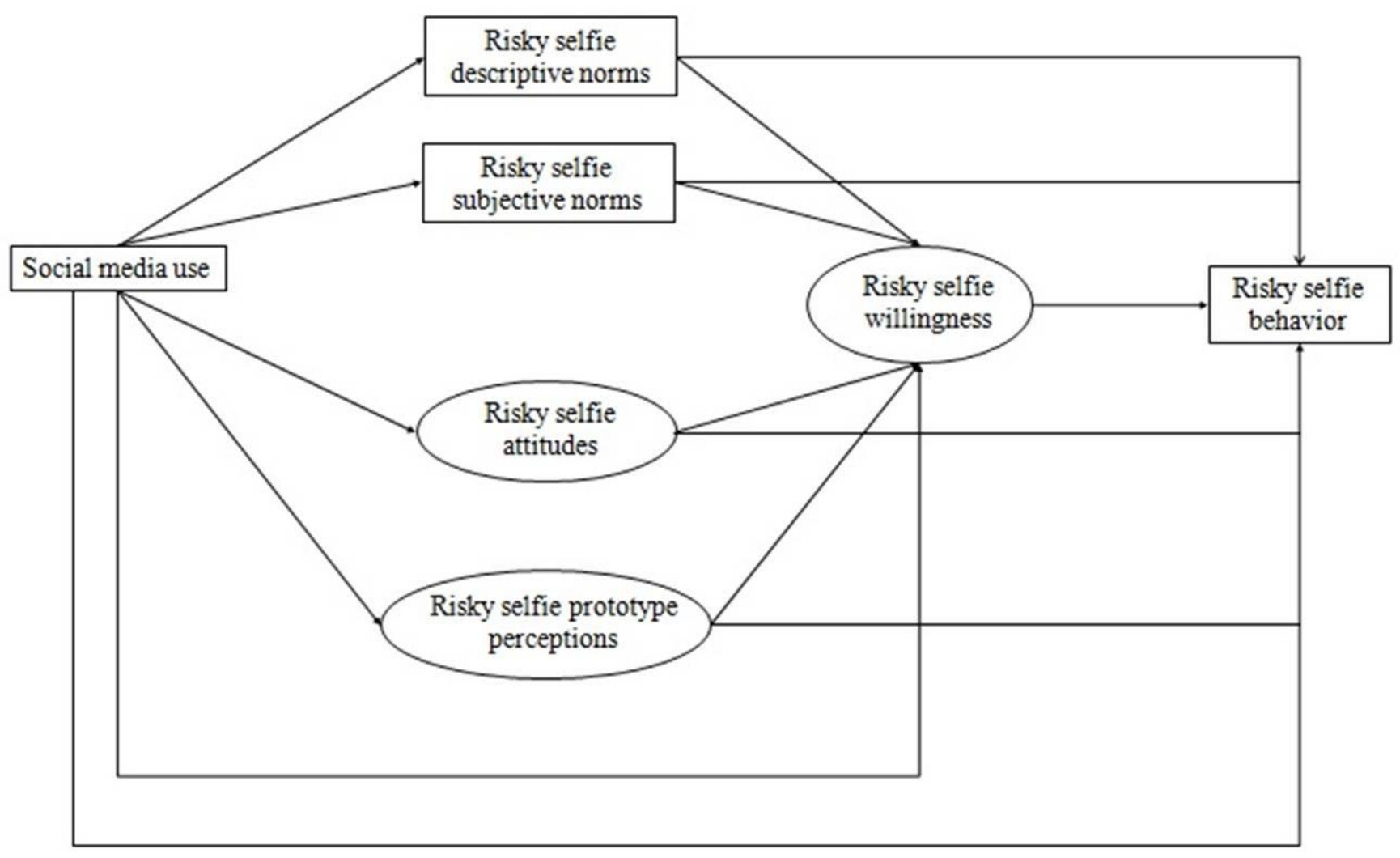

Figure 1. Hypothesized relations between social media use, cognitive factors, risky selfie willingness and behavior. 


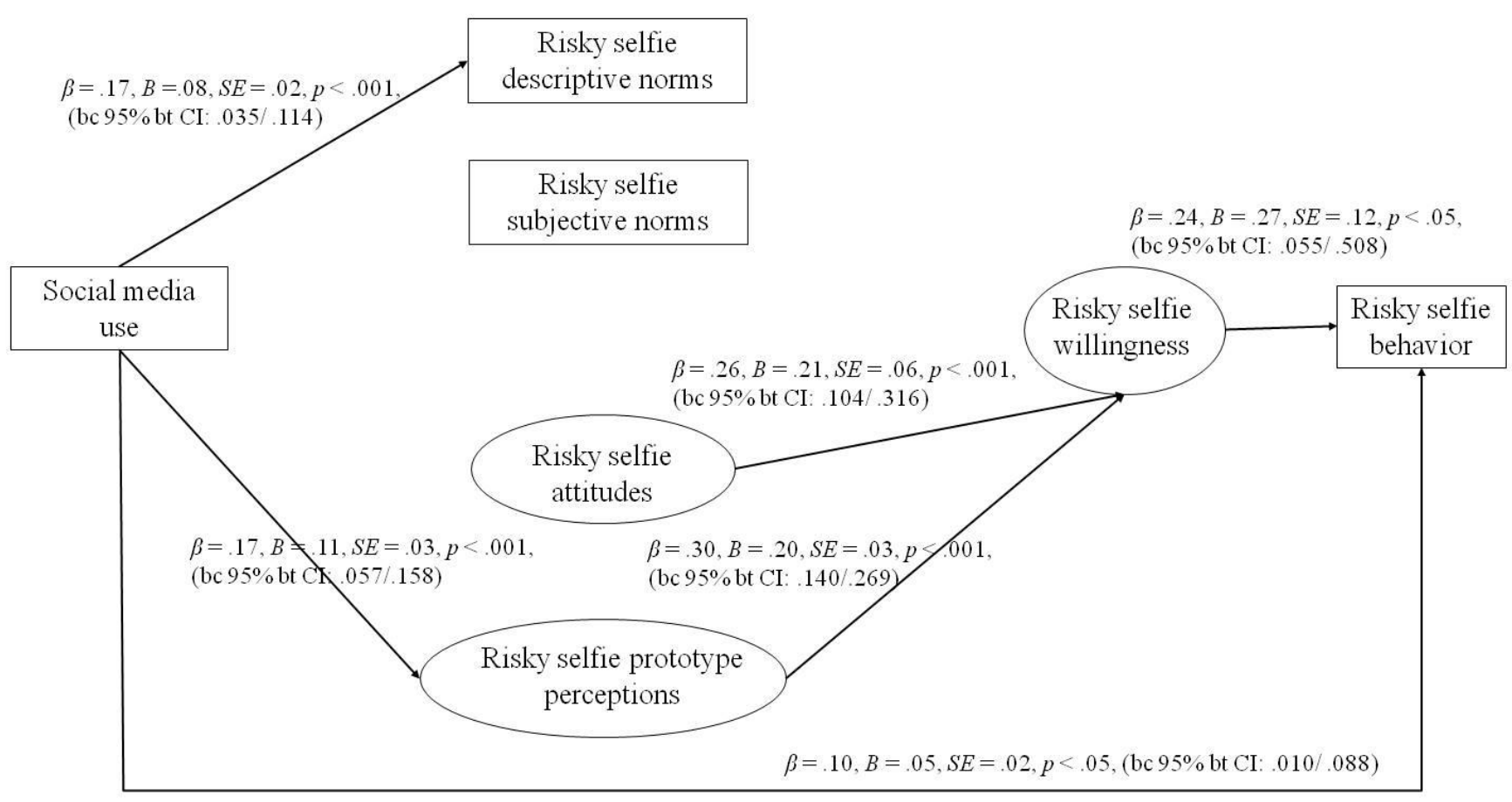

Figure 2. Model examining the relations between social media use, cognitive factors, risky selfie willingness and behavior.

$\beta=$ standardized path coefficient $B=$ unstandardized path coefficient; $p=\mathrm{p}$ values as obtained from the model; bc $95 \%$ bt $\mathrm{CI}=95 \%$ bias-corrected bootstrap confidence interval for unstandardized path coefficients. All displayed paths were significant in the tested model (at $p<.05)$. For clarity, error terms, covariances and measurements are not shown. 